\title{
MECHANISMS OF ANAESTHESIA: A REVIEW
}

\author{
SHELdon H. Roth
}

\begin{abstract}
Anaesthesia is a drug-induced reversible perturbation of neuronal activity. Since a wide variety of structurally unrelated substances are capable of producing this phenomenon, it has been generally accepted that anaesthetics produce their cffects through non-specific hydrophobic interactions. Results of recent studies in whole animal and cellular (membrane) preparations demonstrate that a unitary theory of action does not exist. Anaesthetics can produce a spectrum of activity in the central nervous system, and different agents produce different patterns of activity. At the cellular and membrane level, differential effects have been observed, structural dependent differences occur and optical isomers display very different activities. The perturbation (fluidity change) of membrane components does not appear to be uniform for all anacsthetics. It is concluded that anaesthetics are selective agents, and produce their effects at multiple sites and through a variety of mechanisms.
\end{abstract}

\section{INTRODUCTION}

IN HIS REVIEW "The Present Status of the Theories of Narcosis", Henderson' concluded with the statement "The final chapter in the theories of narcosis (anaesthesia) has as yet to be written." Although this statement was made half a century ago, it remains true to the present day, and will probably do so for many years to come.

Why does the machanism of anaesthesia still remain a mystery? One of the major problems is the lack of a suitable definition for the phenomenon of anaesthesia. This is complicated by the absence of a clear understanding of consciousness. ${ }^{2}$ The anaesthetist regards anaesthesia as a state of unconsciousness accompanied by as few as possible undesirable somatic or autonomic reactions, such as response to painful (surgical) stimuli. ${ }^{3}$ Anaesthesia can also be described as a drug-induced perturbation of normal activity in the central nervous system (CNS) which is completely reversible. ${ }^{4}$ It is a phenomenon that can be produced by a wide variety of chemical substances. The one common modality among these agents is lipid solubility. ${ }^{5}$

Since many excellent reviews have been written on the subject of mechanisms of anaesthesia ${ }^{6-11}$ a complete review of the literature has not been presented. Instead, an attempt has been made to demonstrate that anaesthetics are selective agents, and there are probably multiple

Sheldon H. Roth, Ph.D. Associate Professor, Division of Pharmacology and Therapeutics, Faculty of Medicine, The University of Calgary, Calgary, Alberta, Canada T2N IN4.

Research supported by the Medical Research Council of Canada. 43 mechanisms of anaesthesia. Without a precise definition of the effect (anaesthesia) or of the agent (anaesthetic) it is difficult to provide a concise and complete review. One of the major difficulties in this area of research is the broad nature of the science. The approach in this review, therefore, will be to focus on some of the cellular and membrane effects of anaesthetics. At this level of study, a great deal of information has evolved during the past several years which has made it possible to gain a better understanding of how these drugs affect neuronal and membrane functions. The relevance of most of these data to the phenomenon of general anaesthesia has yet to be resolved; however, the studies have provided considerable support that the mechanisms of anaesthesia are not common for all anaesthetics.

Anaesthetics are usually termed non-specific pharmacological agents. ${ }^{6}$ An anaesthetic has been defined as any agent or drug which is capable of reversibly blocking neural conduction without any significant effect on the resting membrane potential. ${ }^{6}$ This definition could include many chemical substances which are not classified pharmacologically as anaesthetics. In this review, an anaesthetic will be loosely interpreted as any agent that is capable of producing the state of anaesthesia.

The non-specific descriptive term implies that there is no precise interaction of an anaesthetic molecule with a receptor, although it has been suggested that the membrane could be regarded as a receptor. ${ }^{s}$ In general, it has been accepted that anaesthetics simply combine with hydrophobic regions in membranes of excitable cells, and this physical interaction yields a per- 
turbation of membrane structure and function. This perturbation could prevent transmission of excitability necessary for perception and/or interpretation of painful stimuli, consciousness, awareness, memory, etc., thus creating the state of anaesthesia.

\section{Non-Specific Theories of Mechanism}

For nearly a century, it has been generally accepted that all anaesthetics produce their effects by a non-specific mode of action, and that this mechanism was similar for all agents. ${ }^{5}$ The principal reasons for general acceptance of this concept were the observations that a wide variety of chemical agents could produce the effect; there appeared to be no structural requirement for activity other than lipid solubility; a specific recepIor was never identified; nor was a specific chemical antagonist discovered. The excellent correlations of physical properties (e.g. lipid solubility) of the wide variety of agents with anaesthetic activity emphasized the importance of hydrophobic interactions, and focused attention towards a simplistic physical mechanism of action, referred 10 as the Unitary Theory of Anaesthesia.

The Unitary Theory is merely an expression of a correlation and provides little, if any, explanation of mechanism, but rather is a rule for activity (i.e. requirement of lipid solubility) and perhaps directs attention to the hydrophobic characteristic of the site(s) of action.

\section{Sites of Anaesthesic Activity}

Most biological cells are susceptible to the actions of anaesthetics. ${ }^{6.12}$ Therefore it is very likely that most regions of the central nervous system are affected by these agents. Attempts to identify precisely the major regions of the central nervous system (CNS) associated with anaesthesia have not met with much success ${ }^{3.11}$. Numerous studies have demonstrated the ability of anaesthetics to affect a variety of regions in the CNS; for example, cortex, medial thalamus, basal ganglia, hypothalamus, mesencephalic region, hippocampus. ${ }^{13-16}$ There is some evidence to suggest that anaesthetics affect specific regions in the CNS, such as the reticular formation, which in turn influence cortical activity; but it is uncertain whether a loss or depression of ascending sensory information in these regions has anything to do with unconsciousness. "There are regions in the CNS that may be insensitive to the effects of anaesthetics, for example, the dendrodendritic excitatory synapses of olfactory bulb. ${ }^{17}$
In general, most agents are capable of enhancing and ultimately disorganizing spontaneous reticular activity. $4.14,18.19$

Neurophysiological experiments have demonstrated that a single state of anaesthesia does not exist, ${ }^{4.18,20}$ but rather a continuum or progressive alteration of central activity occurs, producing both depression and excitation. ${ }^{18.19}$ It is common to generalize and assume that anaesthesia is purely a depression of neural activity; but depression could be produced by any alteration such as excitation, facilitation or depression at one or more levels of neural function, for example, initiation, amplification, integration or propagation of impulse.

It has been well documented that different anaesthetics can produce different spectra of activity, ${ }^{3}$ and individual anasthetics have been associated with specific electroencephalographic (EEG) patterns. Alteration of either inhibitory or excitatory processes in certain regions of the CNS may result in the major components of the anaesthetic state, such as analgesia, amnesia, muscle relaxation and unconsciousness. ${ }^{4}$

\section{Cellular Effects of Anaesthetics}

The language of the central nervous system may be illustrated simply as transmission of action potentials from one cell to another, and eventually from one region of the CNS to another, or from the periphery to the CNS. This occurs through neurons and across synaptic clefts. The primary site of action of anaesthetics in the CNS is believed to be at the chemical synapse(s). ${ }^{11,21,22}$ This is supported by the observations that many anaesthetics depress synaptic transmission at lower concentrations than required for conduction block in axons. ${ }^{23-25}$

Since general anaesthetics, such as the gaseous and volatile agents, are also capable of blocking axonal conduction, ${ }^{26,27}$ it has been suggested that general anaesthesia is a result of the blockade of fine unmyelinated nerve terminals which would lead to apparent synaptic depression. ${ }^{25}$ This presents a similarity of effect between the local and general anaesthetics. 6

There have been a number of reports demonstrating the depressant effects of anaesthetics on both peripheral and central synapses (see reference 22). A few of these studies have also shown the enhancement ${ }^{28.29}$ or facilitation ${ }^{30}$ of synaptic activity produced by anaesthetics. Depression of release of excitatory neurotransmitter ${ }^{31}$ and increase of inhibitory transmitter ${ }^{17}$ have also been implicated in the synaptic 
effects of anaesthetics. Presumably these effects would occur as a result of pre-synaptic actions of anaesthetics, possibly by interference with a calcium-mediated neurosecretory process. ${ }^{11}$

The responsiveness of the postsynaptic membrane or receptor may also be altered. ${ }^{22}$ This could result from a decrease in chemosensitivity of receptors, ${ }^{6}$ alteration of postsynaptic ionic channels, ${ }^{23,33}$ stabilization of postsynaptic membrane, ${ }^{34,35}$ or inhibition of action potential propagation. ${ }^{36}$ Current data suggest that many sites at the synapse may be involved, and the specific site of action for a certain anaesthetic may be dependent on the structure of the agent. ${ }^{22}$

\section{Interactions of Anaesthetics With Membranes \\ Cellular membrane}

The cellular membrane is regarded to be the major site of action. ${ }^{5}$ Cellular membranes are complex structures consisting of a phospholipid bilayer cmbedded with proteins. ${ }^{37}$ Many of the proteins are essential to membrane function. ${ }^{38}$ Some of the proteins may be immobile, although most are probably in a state of general lateral diffusion. ${ }^{39}$ The interactions between lipids and proteins are not well understood. ${ }^{40}$

Protcins are amphiphatic and thus provide a large number of hydrophobic sites for the anaesthetic molecules within the membrane in addition to the phospholipid bilayer. ${ }^{5}$ Although many studies emphasize the lipid bilayer, ${ }^{5-7}$ it is most probable that more than one region is involved in the anaesthetic-membrane interaction. ${ }^{41}$

\section{Membrane theories of anaesthesia}

A correlation between anaesthetic potency and lipid solubility was first noted independently by Meyer and Overton and provided the basis of the lipid solubility theory or rule of anaesthesia. ${ }^{42}$ It was postulated by Meyer ${ }^{-2}$ that anaesthesia occurred when a critical concentration of anaesthetic was attained in the membrane phase.

Attempts to extend this rule and develop a proper theory soon followed, and the concept of volume of anaesthetic in the membrane phase rather than number of molccules was developed by Mullins. ${ }^{43} \mathrm{He}$ suggested that volume associated with shape and size was the determining factor for activity. If the size of the molecule was suitable, and could fit into the "holes" of the membrane lattice structure, then, when a critical volume was occupied, ionic channels would be blocked, and the excitability of the cell would be depressed. Other molucules which were either too large or not the proper shape would be convulsants, and other molecules which were complementary to the molecules in the membrane would be inert.

This concept of volume was modified by Miller, et al. ${ }^{44}$ and became a mechanistic theory of action known as the Critical Volume Hypothesis, which stated that anaesthesia would result if the volume of a hydrophobic region in the membrane were expanded beyond a critical volume by adsorption of an anaesthetic. This theory suggested expansion to be the mechanism of anaesthesia. Several observations were consistent with this theory, ${ }^{5.6}$ for it was known that anaesthetics could expand monolayers, bilayers, oils, solvents, and even biological membranes. In addition, an opposing force (compression) by high pressure could antagonize or reverse the anaesthetic effect and, therefore, provided support for expansion. ${ }^{44}$ However, the characteristics of pressure reversal may not be similar for all anaesthetics. ${ }^{41,45}$ The change in volume was es. timated to be of the order of 0.5 per cent..$^{46-48}$ It has not yet been established precisely what form of expansion occurs; that is whether the alteration in membrane size is a multi-dimensional or two-dimensional change (see reference 5).

\section{Fluidization of membranes}

In order for the volume (multi-dimensional) or surface area (two-dimensional) of the membrane to change, it is necessary for the resistance to lateral diffusion of molecular components to decrease. This is referred to as fluidization. Fluidization may be regarded as a change in the order of the membrane structure and can be examined using spin probe resonance or fluorescence spectroscopy. In general, most anaesthetics alter the fluidity or order of the membrane, and this implies that anaesthetics induce a transition from one phase to another. ${ }^{49}$ In terms of the lipid bilayer, anaesthetics cause a shift of the gel phase (ordered) to a liquid crystalline phase (disordered or fluid).

Anaesthetic-induced fluidization may affect the excitability of a neuronal membrane in a variety of ways. Anaesthetics may increase the mobility of the entire bilayer, which could induce a membrane expansion ${ }^{5}$ and thereby alter the functions of the proteins. Anaesthetics may affect only certain lipids, for example the phospholipids surrounding the functional proteins (ionophores). It is suggested that these lipids, termed lipid annulus, exist normally in the gel phase retaining the ionic channel in an open 
state. ${ }^{50}$ When these lipids are fluidized or "melted" by an anaesthetic, the channel cannot remain open and therefore excitability is depressed. It has also been proposed that anaesthetics affect the regions where lipids in the gel phase coexist with lipids in the crystalline phase. ${ }^{49}$ These regions are termed lateral phase separations and can be transformed by anaesthetics, which may prevent conformational changes in functional proteins from occurring, thus reducing neural function. ${ }^{49}$ The latter two theories of fluidization are very similar.

Fluidity occurs at clinical concentrations of anaesthetics ${ }^{8}$ and correlates well with biological activity. ${ }^{5}$ However, anaesthetics may order as well as disorder biomembranes, ${ }^{11.51 .52}$ and fluidity may also be dependent on composition of membranes, ${ }^{53.54}$ as well as structure of the perturbing molecule (anaesthetic) ${ }^{55}$ It still remains to be proven whether fluidity of phospholipids can account completely or in part for anaesthetic action.

It is unlikely that perturbation of membrane lipids can account for all of the actions of anaesthetics. Membrane proteins are involved in many functions of the cell. ${ }^{40}$ Anaesthetics may alter protein conformation by interacting directly with the proteins ${ }^{8}$ or indirectly through the lipids. ${ }^{49}$ It has also been suggested that different anaesthetics interact with different sites on functional proteins. ${ }^{36}$

\section{Selectivity of Anaesthetic Actions}

A unitary theory, which proposes that all anaesthetics act by a common mechanism, cannot account for the selectivity of action which is exhibited in the whole animal, ${ }^{13}$ and at the cellular or membrane level. ${ }^{5}$ Although subtle when compared to classic drug-receptor interactions, selectivity of action by anaesthetics suggests that the site(s) is capable of distinguishing slight structural differences.

In clinical anaesthesia, it is well recognized that all anaesthetics do not produce the same effects on peripheral systems such as the respiratory and cardiovascular systems. A variety of patterns of anaesthesia can be observed in the CNS which cannot be accounted for by differences in pharmacokinetics. ${ }^{20.58}$ Anaesthetics can produce both excitation and depression, suggesting selective inactivation or facilitation of specific processes. ${ }^{4}$ Most anaesthetics initially enhance activity in the CNS, then progressivly produce depression. However, anaesthetics do not depress all synapses in the CNS. ${ }^{30}$ The varia- tion in response or spectrum of activity may be a result of selectivity of action at a single site or at multiple sites. ${ }^{8}$ Multiple sites may possess similar but not identical physical properties, which would provide an explanation for the correlation which exists between potency and lipid solubility. ${ }^{\text {s8 }}$

In addition to lipid solubility, activity may be related to structure of the anaesthetic molecule. ${ }^{59}$ Structure activity relationships have been well demonstrated for a variety of substances including barbiturates, ${ }^{60-62}$ steroid anaesthetics, ${ }^{63}$ fluorinated ethers and alkanes, ${ }^{58,64}$ ketamine isomers, ${ }^{65}$ and long chain alcohols. ${ }^{51}$

\section{Cellular Effects}

A variety of responses can be elicited by anaesthetics at the cellular level. In addition to the biphasic responses of excitation and depression, which are usually related to concentration, ${ }^{66}$ differences in response are observed with different structures. ${ }^{12.62}$ Selectivity also occurs on different cell types, ${ }^{67}$ suggesting different neurones may possess variable specific properties. Using isolated cultured neurones, Barker and his associates have shown significant differences in activity between the anaesthetic and anticonvulsant barbiturates, ${ }^{68}$ and stereospecific barbiturates. ${ }^{62}$ Landau and colleagues, using isolated neuromuscular preparations, have reported differential effects of the anaesthetic and convulsant volatile agents. ${ }^{58}$

Changes in fluidity of the membrane have been shown to be sensitive to structure. ${ }^{52}$ Miller, et al. introduced the terminology "fluidising efficacy" to describe the wide variations observed in fluidity changes of phospholipid bilayers with different substances. ${ }^{53}$

In our own laboratory, we have examined the effects of several different anaesthetic agents on the charactersitic firing output of an isolated neuron - the stretch receptor of the crayfish. ${ }^{12,69,70}$ It has been observed that different anaesthetics can selectively alter the activity (behaviour) of the neuron. The complete spectrum of excitation and depression that occurs in intact animals and man was observed at the level of the single cell. These biphasic effects were time and concentration dependent. In addition to activation and depression, a third phase was observed with some anaesthetics. This phase was characterized by an alteration of the normal rhythmical firing pattern to one consisting of bursts. This disruptive phase can be produced by the short chain alcohols $\left(\mathrm{C}_{2}-\mathrm{C}_{7}\right)$ and the volatile 
anaesthetics. The burst patterns occurred at concentrations just below those required to produce complete depression of firing. Most dramatic, however, was the difference in burst patterns for the different anaesthetics. For example, $500 \mathrm{mM}$ ethanol would produce a burst consisting of between $10-20$ spikes. The bursts also fired in a rhythmical fashion. Halothane $(20 \mu \mathrm{M})$ produced very arrhythmical bursts of high frequency, each burst consisting of a variable number of spikes. In contrast, some anaesthetics would never produce a burst activity, but would enhance and depress firing rate. Examples of this group are local anaesthetics and pentobarbitone. Recent studies using intracellular techniques ${ }^{71}$ suggest the drug-induced alterations of neuronal behaviour may be related to selective actions at the membrane level.

\section{Multiple Sites of Action}

The neural membrane is not a bulk phase, ${ }^{7}$ but possesses microheterogeneous regions ${ }^{59}$ and thus is capable of a high level of structural discrimination. 8,9 Liposomes, which are not as complex as biological membranes, also appear to be able to recognize differences in molecular structure. ${ }^{72}$ The ability of membranes to discriminate structural differences may explain why some lipid soluble molecules are not active, and others are only partially active.

The spectrum of activity of anaesthetics, structural discrimination, differences in effect of optical isomers and differences between anaesthetics on specific preparations suggest multiple sites of action. ${ }^{11}$

The variation in response of a single cell to different anaesthetics, differences of action of optical isomers and differences between different physiological preparations suggest that there are multiple sites and multiple mechanisms of action. ${ }^{41}$ This concept is not in support of a unitary theory of anaesthesia. Anaesthetic agents, although historically termed non-specific agents, do possess very selective actions at the molecular level.

The mechanisms of action are as yet undefined; thus the final chapter in the mechanisms of anaesthesia (narcosis) remains unwritten.

\section{REFERENCES}

1. Henderson, V.E. The present status of the theories of narcosis. Physiological Reviews 10: $171-220$ (1930).

2. Millar, R.A. Anaesthetic actions. Br. J. Anaesth. 47: 335 (1975).
3. Clark, D.L. \& Rosner, B.S. Neurophysiologic effects of general anesthetics. I. The electroencephalogram and sensory evoked response in man. Anesthesiology 38: 564-582(1973).

4. StOCKARD, J, \& BiCKFORD, R. The neurophysiology of anesthesia. In A Basis and Practice of Neuroanesthesia, Ed. E. Gordon, pp. 3-46. Amsterdam: Excerpta Med. (1975).

5. Roth, S.H. Physical mechanisms of anesthesia. Ann. Rev. Pharmacol. Toxicol. 19: 159-178(1979).

6. SeEman, $P$. The membrane actions of anesthetics and tranquillizers. Pharmacol. Rev. 24: 583-655 (1972).

7. Miller, J.C. \& Miller, K.W. Approaches to the mechanisms of action of general anesthetics. In Physiological and Pharmacological Biochemistry, Biochemistry Series One, Vol. 12, Ed. H.F.K Blaschko, pp. 33-76. London: Butterworth (1975).

8. KaUfMAN, R.D. Biophysical mechanisms of anesthetic action: historical perspective and review of current concepts. Anesthesiology 46 : 49-62 (1977).

9. Halsey, M.J., Millar, R.A.\& Sutton, J.A. eds. Molecular mechanisms in general anesthesia. Edinburgh: Churchill-Livingstone (1974)

10. FINK, B.R. ed. Molecular mechanisms of anesthesia, progress in anesthesiology, Vol. I. New York: Raven Press (1975).

11. Richards, C.D. In search of the mechanisms of anaesthesia. Trends in Neuroscience 3: 9-13 (1980).

12. Roth, S.H. Membrane and cellular actions of anesthetic agents. Federation Proc. 39: 1595-1599 (1980).

13. ROSNER, B.S. \& Clark, D.L. Neurophysiologic effects of general anesthetics. II. Sequential regional actions in the brain. Anesthesiology 39 : 59-81 (1973).

14. Mori, K., Kawamata, M., Miyajima, S. \& Fusita, M. The effects of several anesthetic agents on the ncuronal reactive properties of thalamic relay nuclei in the cat. Anesthesiology 36: 550-557 (1972).

15. Dafny, N. \& Rigor, B.M. Dose effects of ketamine on photic and acoustic field potentials. Neuropharmacol. 17: 851-862(1978).

16. Shimoji, K., Matsuki, M., Shimizu. H. MaruYama, Y. \& ADIA, S. Dishabituation of mesencephalic reticular neurons by anesthetics. Anesthesiology 47: 349-352 (1977).

17. Nichol, R.A. The effects of anesthetics on synaptic excitation and inhibition in the olfactory bulb. J. Physiol. 233: 803-814 (1972).

18. WINTERS, W.D. Neuropharmacological studies of drug-induced states of CNS excitation and depression. In Drugs and the Brain, Ed. P. Black, pp. 93-114. Baltimore: Johns Hopkins Univ. Press (1969).

19. Winters, W.D., Ferrar-Allado, T., Guzman-Flores, C. \& Alcaraz, M. The calaleptic state induced by ketamine: a review of the neuropharmacology of anesthesia. Neuropharmacology 11: 303-315(1972).

20. Paton, W.D.M. Unconventional anesthetic molecules. In Reference 9, pp. 48-64.

21. WALL, P.D. The mechanisms of general anesthesia. Anesthesiology 28: 46-52 (1967). 
22. RICHARDS, C.D. The action of anaesthetics on synaptic transmission. Gen. Pharmacol. 9: 287-293 (1978)

23. Larrabee, M.G. \& Posternak, J.M. Selective action of anesthetics on synapses and axons in mammalian sympathetic ganglia. J. Neurophysiol. 15: $91-114$ (1952).

24. Sraiman, A. \& Seeman, P. Nerve fibre diameter determines the nerve-blocking concentrations of anesthetics, alcohols, anticonvulsants, barbiturates and narcotics. Can. J. Physiol. Pharmacol. 52:535-550(1974).

25. Staiman, A. \& Seeman, P. Conduction-blocking concentrations of anesthetics increase with nerve axon diameter: studies with alcohol, lidocaine and tetrodotoxin on single myelinated fibers. J. Pharmacol. Exp. Ther, 20I: 340-349 (1977).

26. Carpenter, F.G. Anesthetic action of inert and unreactive gases on intact animals and isolated tissues. Amer. J. Physiol. 178: 505-509 (1954).

27. Roth, S.H., Smith, R.A. \& PATON, W.D.M. Pressure antagonism of anaesthetic-induced conduction failure in frog peripheral nerve. $\mathrm{Br}$. J. Anaesth. 48: 621-628 (1976)

28. SMAJE, J.C. General anaesthetics and the acetylcholine-sensitivity of cortical neurones. $\mathrm{Br}$. J. Pharmacol. 58: 359-366 (1976).

29. EVANS, R.H. Potentiation of the effects of GABA by pentobarbitone. Brain Research 171: 113-120 (1979).

30. Morris, M.E. Facilitation of synaptic transmission by general anesthetics. J. Physiol. 284: 307-325 (1978).

31. WEAKLY, J.N. Effect of barbiturates on "quantal" synaptic transmission in spinal motoneurones. $J$. Physiol. 204: 63-77 (1969)

32. ZoRYChtA. E. \& CAPEK, R. Depression of spinal monosynaptic transmission by diethyl ether: quantal analysis of unitary synaptic potentials. J. Pharmacol. Exp. Ther. 207: 825-836 (1978)

33. Torda, T.A. \& Gage, P.W. Postsynaptic effect of I. $V$. anaesthetic agents at the neuromuscular junction. Br. J. Anaesth. 49: 771-776 (1977).

34. SomJEN, G.G. Effects of anesthetics on spinal cord of mammals. Anesthesiology 28: 135-143 (1967).

35. Chalazonitis, N. Selective actions of volatile anesthetics on synaptic transmission and autorhythmicity in single identifiable neurons. Anesthesiology 28: 111-122 (1967).

36. Saro, M., Austin, G.M. \& YaI, H. Increase in permeability of the post-synaptic membrane to potassium produced by "Nembutal". Nature 215 : 1506-1508 (1967).

37. Singer, S.J. \& Nicolson, G.L. The fluid mosaic model of the structure of cell membranes. Science 175: 720-731 (1972)

38. Singer, S.J. The proteins of membranes. J. Colloid and Interface Science 58: 452-458 (1977)

39. FaheY, P.F., Koppel, D.E., Barak, L.S., Wolf, D.E., Elson, E.L. \& WEBB, W.W. Lateral diffusion in planar lipid bilayers. Science 195: 305-306 (1977).

40. Gennis, R.B. \& Jones, A. Ptotein-lipid interactions. Ann. Rev. Biophys. Bioeng. 6: 195-238 (1977).

41. Halsey, M.J., Wardley-Smith. B. \& Green, C.J. Pressure reversal of general anaesthesia - a multi-site expansion hypothesis. Br. J. Anaesth. 50: 1091-1097 (1978).

42. Meyer, K.H. Contributions to the theory of narcosis. Trans. Faraday Soc. 33: 1062-1068 (1937).

43. Mullins, L.J. Some physical mechanisms in narcosis. Chem. Rev. 54: 289-323 (1954)

44. Miller, K.W., Paton, W.D.M., Smith, R.A.\& SMITH, E.B. The pressure reversal of anaesthesia and the critical volume hypothesis. Mol. Phar. macol. 9: 131-143 (1973).

45. Roth, S.H. Anesthesia and pressure: antagonism and enhancement. In Molecular Mechanisms of Anesthesia. Progress in Anesthesiology, Vol. I, pp. 405-420. New York: Raven (1975).

46. Roth, S.H. \& SeEman, P. Anesthetics expand erythrocyte membranes without causing loss of potassium. Biochim. Biophys. Acta 255: 190-198 (1972).

47. Lever, M.K. Miller, K.W., Paton, W.D.M.\& SMITH, E.B. Pressure reversal of anaesthesia. Nature (London) 231: 368-371 (1071).

48. Roth, S.H. \& SeEmAN, P. Anesthetics expand erythrocyte membranes without causing loss of potassium. Biochim. Biophys. Acta 255: 190-198 (1972).

49. Trudell, J.R. A unitary theory of anesthesia based on lateral phase separations in nerve membranes. Anesthesiology 46: 5-10 (1977).

50. LEE, A.G. Model for action of local anaesthetics. Nature (London) 262: 545-548 (1976).

51. Pringle, M.J. \& Miller, K.W. Differential effects on phospholipid phase transitions produced by structurally related long-chain alcohols. Biochemistry 18: 3314-3320 (1979).

52. RosenberG, P.H., Jansson, S-E. \& Gripenberg, $J$. Effects of halothane, thiopental and lidocaine on fluidity of synaptic plasma membranes and artificial phospholipid membranes. Anesthesiology 46: 322-326 (1977).

53. Miller, K.W. \& PANG, K-Y.Y, General anesthetics can selectively perturb lipid bilayer membranes. Nature 263: 253-255 (1976).

54. Simon, S.A., Mcintosh, T.J., Bennett, P.B. \& Shrivastav, B.B. Interaction of halothane with lipid bilayers. Mol. Pharmacol. 16: 163-170(1979).

55. Pringle, M.J. \& Millet, K.W. Structural isomers of tetradecenol discriminate between the lipid fluidity and phase transition theories of anesthesia. Biochem. Biophys. Res. Comm. 85: 1192-1198 (1978)

56. Richards, C.D., Martin, K., Gregory, S. Keigutley, C.A., Hesketh, T.R., SMith, G.A., WARREN, G.B. \& METCAlfe, J.C. Degenerate perturbations of protein structure as the mechanism of anesthetic action. Nature (London) 276 : $775-779$ (1978).

57. Sinclair, J.G. \& TiEN, A.F. Neuronal responses to ketamine administered microiontophoretically or intraperitoneally in the rat. Gen. Pharmac. 10: 51-55 (1979).

58. Richter, J., Landau, E.M. and Cohen, S Anaesthetic and convulsant ethers act on different sites at the crab neuromuscular junction in viro. Nature 266: 70-71 (1977).

59. Jain, M.K., Gleeson, J., Upreti, A. \& Upreti, G.C. Intrinsic perturbing ability of alkanols in lipid bilayers, Biochim. Biophys, Acta. 509: 1-8 (1978). 
60. Andrews, P.R., Jones, G.P. \& Lodge. D. Convulsant, anticonvulsant and anesthetic barbiturates. 5-ethyl-5-(-3'-methyl-but-2'-enyl)-barbituric acid and related compounds. Europ. J. Pharmacol. 55: 115-120(1979).

61. Hertz, L. \& SASTRY, B.R. Inhibition of $\chi$ aminobutyric acid uptake into astrocytes by pentobarbital. Can. J. Physiol. Pharmacol. 56: 1083-1087 (1978).

62. Huang, L-Y.M. \& Barker, J.L. Pentobarbital stereospecific actions of $(+)$ and $(-)$ isomers revealed on cultured mammalian neurons. Science 207: 195-197 (1980).

63. PHILLIPS, G.H. Structure activity relationships in steroidal anesthetics. In reference 9 , pp. 32-46.

64. Cohen, S., Goldschmid, A., Shtacher, G. SRebrenik, S. \& GitTer, S. The inhalation convulsants: a pharmacodynamic approach. Mol. Pharmacol. 1/: 379-385 (1975)

65. White, P.F., HAM, J., WAY, W.L. and TreVor, A.J. Pharmacology of ketamine isomers in surgical patients. Anesthesiology 52:213-239 (1980).

66. Gage, P.W. \& Hamill, O.P. Effects of several inhalation anesthetics on the kinetics of postsynaptic conductance changes in mouse diaphragm. Br. J. Pharmac. 57: 263-272 (1976)
67. Kleinhaus, A.L. and Pritchard, J.W. Interaction of divalent cations and barbiturates on four identified leech neurons. Comp. Biochem. Physiol. 63c: 351-357 (1979).

68. MacDonald, R.L. \& Barker, J.L. Different actions of anticonvulsant and anesthetic barbiturates revealed by use of cultured mammalian neurons. Science 200: 775-777 (1978)

69. Roth, S.H. \& MacIVER, B. Alteration of neuronal behaviour by anesthetic agents. Ptoc. West. Pharmacol. Soc. 22: 47-52(1979).

70. Rort, S.H. The differential effects of anesthetics on neuronal activity. Molecular Mechanisms of Anesthesia. Progress in Anesthesiology, Vol. 2. New York, Raven Press (1908), in press.

71. Maclver, M.B. \& Roth, S.H. The effects of halothane on the neuronal output, membrane properties and synaptic transmission of an isolated neuron. Proc. West. Pharmacol. Soc. 23: 405-411 (1980).

72. LAWRENCE, D.K. \& GILL. E.W. Structurally specific effects of some steroid anesthetics on spin-labeled lipsomes. Mol. Pharmacol. 1/: 280-286(1975).

\section{RÉSUMÉ}

L'anesthésie est une perturbation réversible d'origine médicamenteuse de l'activité neurologique. Comme une grande variété de substances non apparentées structurellement peuvent produire ce phénomène, il est généralement accepté que les agents anesthésiques produisent leurs effets par des interactions non spécifiques à caractère hydrophobique. Les rếsultats de travaux récents, tant chez l'animal que ceux effectués sur des montages cellulaires (niveau de la membrane) ont démontré l'absence d'une théorie unique pour expliquer le mécanisme d'action des anesthésiques. Les anesthésiques peuvent exercer leur activité à plusieurs sites du système nerveux central et différents agents exercent des effets différents. Au niveau de la membrane et de la cellule, des effets différents ont été observés, on note des différences selon la structure moléculaire et des isomères optiques exercent des actions très différentes. Les modifications (propriétés fluidiques) des composants de la membrane ne semblent pas uniformes avec tous les agents. On conclut que les agents anesthésiques sont des agents sélectifs qui produisent leurs effets à différents sites et par des mécanismes variés. 